\title{
Are mini-games within RuneScape gambling or gaming?
}

\author{
Mark D. Griffiths ${ }^{1}$ and Rosie King ${ }^{2}$ \\ ${ }^{1}$ International Gaming Research Unit, Psychology Division \\ Nottingham Trent University, United Kingdom \\ Email: mark.griffiths@ntu.ac.uk
}

${ }^{2}$ Queen’s Mary College, Basingstoke, United Kingdom 


\section{Are mini-games within RuneScape gambling or gaming?}

Since the beginning of the 1990s until the present day, many scholars have observed that there are psychological and behavioral similarities between gambling and video game playing - particularly in relation to slot machines and video games ${ }^{1-8}$. Arguably, the main difference between gambling and video gaming is that video gamers try to accumulate as many points as possible whereas gamblers try to accumulate as much money as possible. In fact, almost 25 years ago, Griffiths ${ }^{2}$ suggested that playing video games could be considered as a nonfinancial form of gambling. One reason for this is that video games share many of the same structural characteristics as recognized forms of gambling, most notably gaming machines. The term 'structural characteristics' refers to those elements of an activity that either induce the person to play or are inducements to continue playing (i.e., characteristics that are responsible for reinforcement, may satisfy a player's needs and may actually facilitate playing).

Given these similarities, it has also been observed that over the last decade, gambling and gaming technologies have begun to converge with video games featuring gambling-like elements, and gambling games featuring video gaming-like elements ${ }^{4}$. Many of the newer convergent gambling-gaming forms include such activities as online penny auctions ${ }^{9}$ and gambling-type activities on social networking sites (i.e., 'social gaming') ${ }^{10}$. With regard to video gaming including gambling-like elements, King, Delfabbro, Derevensky and Griffiths ${ }^{11}$ noted that simulated gambling activities and gambling themes have a substantial presence in many modern video games. According to King and colleagues ${ }^{11}$, gambling content in video games may be categorized according to the following three categories:

- Standard gambling simulation, a digitally simulated interactive gambling activity that is structurally identical to the standard format of an established gambling activity, such as blackjack or roulette;

- Non-standard gambling simulation, an interactive gambling activity that involves the intentional wagering of in-game credits or other items on an uncertain outcome, in an activity that may be partially modelled on a standard gambling activity but which 
contains distinct player rules or other structural components that differ from established gambling games;

- Gambling references, the appearance of non-interactive gambling material or gamblingrelated paraphernalia/materials within the context of the video game.

In regard to the second of these categories, it could be argued that the online game RuneScape features mini-games that are non-standard gambling simulations. The remainder of this paper will evaluate the extent to which this is true. RuneScape is a fantasy-based MMPORPG (massively multiplayer online role playing game) that was released online in January 2001 by the UK-based company Jagex Ltd. There are well over 200 million Runescape accounts and is the world's largest free MMORPG ${ }^{12}$. Over the last few years new mini-game features to the game have been introduced that could be argued to be a type of gambling - most noticeably 'Squeal of Fortune' (introduced February 2012) and then replaced by 'Treasure Hunter' (in February 2014).

\section{Brief overview of Squeal of Fortune $e^{13}$}

The mini-game 'Squeal of Fortune' (SoF) was modeled on 'wheel of fortune' games. SoF members were typically given two free spins a day on a virtual wheel whereas non-members playing in the free worlds only got one free spin a day (and reset every midnight at universal time co-ordinated [UTC]). Winners of SoF were rewarded with helpful in-game items (e.g., coins, armor, weapons, etc.). By clicking an on-screen button, players could activate the virtual wheel and then press the button again to stop the wheel. On stopping the wheel, players would either win a prize that they could either claim, convert into in-game coins, or discard the prize.

In April 2012, new ways were introduced for players to get additional spins on SoF. As well as free daily spins, players could also obtain spins through skillful gameplay, as well as the option to purchase spins. Players who bought the silver or gold membership package got three free spins of the wheel a day (compared to two for normal members and one for nonmembers). Players could also get a free SoF spin on a monthly basis if they participated in new games inside RuneScape (such as 'Troll Invasion') or get two free spins if they completed an in-game quest. In September 2012, a free extra spin was introduced if players completed a 
daily in-game challenge. Players were also given the opportunity to buy 'bonds' for gold coins or money that could be redeemed for a further 8 spins of the wheel. Free spins could not be 'rolled over' and had to be used on the same day and the winners were generated randomly.

Extra spins of the SoF could also be bought in groups of 10 (\$4.99), 20 (\$9.99), 40 (\$19.99), 100 (\$49.99) or 200 spins (\$99.99) [prices shown in US dollars here and in the rest of the paper]. Players also got 5 bonus spins if a player bought 20 spins, 35 bonus spins for buying 40 spins, 100 bonus spins for buying 100 spins, and 250 bonus spins for buying 200 spins). In the US, the maximum number of spins that could be bought was $\$ 200$ a day and $\$ 500 \mathrm{a}$ week. Many players viewed SoF as a form of real world trading because many items from SoF either have a significant gold or 'experience' value.

\section{Brief overview of Treasure Hunter ${ }^{14}$}

As noted earlier, the mini-game 'Treasure Hunter' (TH) replaced SoF in February 2014. To get in-game prizes, players had to get keys to open chests rather than spinning a wheel. Originally, to participate in TH, players had to play in a members' world. Players that tried to play TH in a free world are given the message: "As a member, you are eligible for improved prizes, so please play Treasure Hunter on a members' world instead." However, in April 2014, TH was reformulated and for the first time, members' prizes could be claimed by those playing in a free world also.

In $\mathrm{TH}$, five chests can be opened, each containing one of five different gems (going from most common to least common - white, yellow, orange, red, or purple gem - with white being the most common and purple being the rarest). After obtaining a key, players select a chest (not knowing what gem is inside the chest), and open it. The player is then given the option of storing the prize in the bank, discarding the prize, collecting the prize later, or cashing out for in-game currency. There are a number of different ways to gain TH keys (free daily keys, keys obtained through skillful gameplay, and buying keys). Like SoF, members get two free keys a day and those playing in free worlds only get one free key a day. Those players paying to be in the silver or gold Premier Club get three free keys a day. 
As with SoF, (i) TH is reset every night at midnight (UTC), (ii) free keys have to be used on the day, (iii) one monthly free key can be earned by playing 'Troll Invasion', (iv) players can buy bonds for in-game gold coins or currency, and (v) the winners are generated randomly (as noted twice on RuneScape's TH information home webpage ${ }^{15}$ ). After completing any daily challenge, players receive an extra key, and after completing any in-game quest, players receive two additional keys. Keys can be bought in bundles of 15 (\$4.99), 35 (\$9.99), 75 (\$19.99), 200 (\$49.99) or 450 keys (\$99.99). The maximum number of keys that can be bought is $\$ 200$ a day and $\$ 500$ a week. Keys can also be earned by watching advertisements, buying products, and completing surveys (and accessed via the 'Earn keys' option). As with SoF, TH prizes include in-game skilling items, weapons, bonus experience stars, etc. or can be converted to in-game currency.

\section{Are RuneScape's mini-games gambling or gaming?}

The legal definition of gambling in Great Britain is contained in s.3 of the Gambling Act 2005. It notes that gambling includes "gaming", "betting" or "participating in lottery". Gaming is defined by s.6 of the 2005 Act as "playing a game of a chance for a prize" while betting involves the process of placing or accepting a bet on anything other than financial services (s.10(1) Gambling Act 2005) that remains uncertain to at least one party of the transaction at the time of the bet (S.9(2)a and s.9(3)b Gambling Act 2005). By this definition alone, it would appear that the both 'Squeal of Fortune' and 'Treasure Hunter' are forms of gambling if purchases to participate are made (rather than being given free spins or keys, or earning them through skillful gameplay).

More widely, there are a number of common elements that occur in the majority of gambling instances that distinguish 'true' gambling from mere risk-taking ${ }^{16}$. These include: (i) the re-allocation of wealth (i.e., the exchange of money [or something of financial value] usually without the introduction of productive work on either side, (ii) winners gain at the sole expense of losers, (iii) the exchange is determined by a future event, which at the time of staking money (or something of financial value) the outcome is unknown, (iv) the result is determined (partly) by chance, and (v) losses incurred can be avoided by simply not taking part in the activity in the first place. Again, using these criteria, both 'Squeal of Fortune' and 'Treasure Hunter' are forms of gambling (as the prizes won clearly have a financial value as 
argued below).

The Gambling Commission ${ }^{17}$ in Great Britain highlighted that they believe the mini-games within Runescape to be 'social gaming' and not a game of chance and therefore out of their jurisdiction in relation to the regulation of the game. The Gambling Commission have also communicated in personal email communications to the second author that RuneScape bonds have no intrinsic value outside of Runescape under the terms of the British Gambling Act and therefore is not gambling. The Gambling Commission ${ }^{17}$ also note on their website that:

"We are not saying there are no risks in social gaming, nor are we saying that this ends our interest in the issue. We are simply saying that our current assessment of the available evidence is that there is no persuasive reason for us to take regulatory action, in effect to change from maintaining a watching brief. We will continue to monitor emerging evidence, and we are prepared to change this position if the evidence warrants it".

However, there are instances when the bonds and prizes won do have value outside of the game. Bonds that are purchased with real life currency can be sold to another player for an in-game sum of money. Bonds and prizes can also be redeemed within the game for real life services. These services are not just limited to the buying of game-related merchandise such as the buying of card games like Top Trumps $s^{18}$, but also attendance at offline RuneScape events such as RuneFest ${ }^{19}$, hotel rooms ${ }^{19}$, and even plane tickets ${ }^{19}$. The bonds can also be used to pay for postage and packing of items bought outside the game. Players can also donate the bonds to charity (in which Jagex contributes the full value of the bond to the charity chosen by the player ${ }^{20,21}$. These examples clearly demonstrate that the bonds do have specific financial value in some circumstances outside the game and impact on real world activities. More specifically, they demonstrate that the financial value of the bonds and prizes can be used outside the game itself.

\section{Other issues of potential concern}

Another issue of potential concern about RuneScape is that it is played by a significant minority of adolescents. Statistics show that $1 \%$ of players are below the age of 13 years, $8 \%$ are between 13 and 15 years, 24\% are between 16 and 18 years, 44\% between 19 and 26 years, and the remainder $(23 \%)$ over 26 years $^{22}$. Given that gambling is an adult activity, steps 
should arguably be taken by the operators of RuneScape to block minors from engaging in such activities. Various news stories around the world have claimed teenagers have incurred large debts from "gambling" on games within RuneScape. For instance, in 2012, a 15-year old boy from Sydney spent $\$ 2000$ on Squeal of Fortune ${ }^{23}$. Another Australian news report claimed that RuneScape was "an online casino aimed at children... with marketing aimed at habituating and incentivising gambling, directly aimed at kids" ${ }^{24}$. The article also reported that many RuneScape are particularly aggrieved that new players can buy their way to success within the game. Another concern is that when playing TH, players constantly receive advertising and marketing messages such as "Your next key could win one of these prizes", and then links the player to another webpage where the player can immediately purchase more keys. Anyone of any age (even in the free world version) is subject to the same in-game advertising and marketing to get the player to buy keys.

\section{Conclusions}

This brief paper has tried to argue that the mini-games of 'Squeal of Fortune' and 'Treasure Hunter' within the online game RuneScape is another example of convergence between gambling and gaming. These games appear to meet the criteria for gambling as set out in s.3 of the Gambling Act 2005 as well as broader criteria found in the gambling studies literature. It was also argued that the bonds and prizes bought and won while playing RuneScape minigames do have a financial value outside of the game and therefore go beyond the definition

of social gaming and is an activity that should perhaps be regulated by the Gambling Commission in Great Britain (and elsewhere in the world). It was also highlighted that adolescents can and do play RuneScape and that they perhaps need protection from both the in-game advertising and marketing that takes place while playing RuneScape as well protection from playing gambling-type games within the game itself.

\section{References}

(1) S.E. Fisher, Identifying video game addiction in children and adolescents. 19 ADDICTIVE BEHAVIORS 545-553 (1994). 
(2) M.D. Griffiths, Amusement machine playing in childhood and adolescence: A comparative analysis of video games and fruit machines. 14 J ADOLESCENCE 5373 (1991).

(3) M.D. Griffiths, The relationship between gambling and videogame playing: A response to Johansson and Gotestam. 96 PSYCHOL REPORTS. 644-646 (2005).

(4) M.D. Griffiths, D.L. King and P.H. Delfabbro, P.H. (2009). Adolescent gamblinglike experiences: Are they a cause for concern? 27 EDUCATION AND HEALTH. 27-30 (2009).

(5) M.D. Griffiths, D.L. King and P.H. Delfabbro. The technological convergence of gambling and gaming practices. In D.C.S Richard, A. Blaszczynski and L. Nower, L. (Eds.). THE WILEY-BLACKWELL HANDBOOK OF DISORDERED GAMBLING 327-346 (2014).

(6) A. Johannson, A. and K.G. Gotestam, Problems with computer games without monetary reward: similarity to pathological gambling. 95 PSYCHOL REPORTS. 641-650 (2004).

(7) D.L. King, P.H. Delfabbro and M.D. Griffiths, Video game structural characteristics: A new psychological taxonomy. 8 INT'L J MENTAL HEALTH AND ADDICTION. 90-106 (2010).

(8) D.L. King, P.H. Delfabbro and M.D. Griffiths, The convergence of gambling and digital media: Implications for gambling in young people. $26 \mathrm{~J}$ GAMBLING STUD. 175-187 (2010).

(9) M.D. Griffiths and M. Carran, Are online penny auctions a form of gambling? 19 GAMING L. REV \& ECON. 190-196 (2015).

(10) M.D. Griffiths, Adolescent gambling via social networking sites: A brief overview. 31 EDUCATION AND HEALTH. 84-87 (2013).

(11) D.L. King, P.H. Delfabbro, J. Derevensky and M.D. Griffiths, A review of Australian classification practices for commercial video games featuring simulated gambling. 12 INT'L GAMBLING STUD. 231-242 (2012)

(12) RuneScape. WIKIPEDIA (2015). < <https://en.wikipedia.org/wiki/RuneScape> (last accessed Sept. 8, 2015) 
(13) Squeal of Fortune. RUNESCAPE WIKIA (2015).

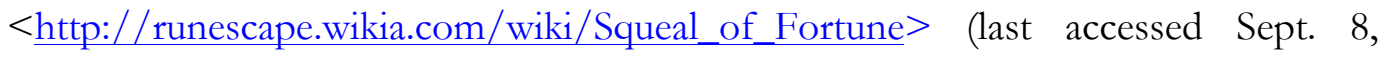
2015)

(14) Treasure

Hunter. RUNESCAPE WIKIA

(2015).

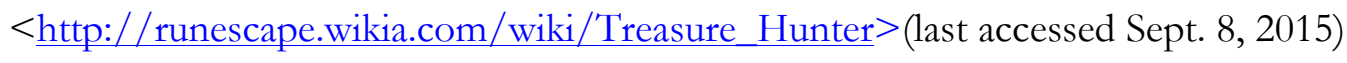

(15) Treasure hunter. RUNESCAPE.COM (2015).

$<$ http://services.runescape.com $/ \mathrm{m}=$ rswiki/en/Treasure_Hunter $>$ (last accessed Sept. 8, 2015)

(16) M.D. Griffiths. ADOLESCENT GAMBLING (1995).

(17) Explaining our approach to social gaming. GAMBLING COMMISSION (2015).

$<\underline{\text { http://www.gamblingcommission.gov.uk/Gambling-data-analysis/Social- }}$

media/Explaining-our-approach-to-social-gaming.aspx $>$ (last accessed Sept. 8, 2015)

(18) What is Top Trumps? RUNESCAPE.COM (2015).

<http://www.runescape.com/top_trumps $>$ (last accessed Sept. 8, 2015)

(19) Come to RuneFest free with bonds. RUNESCAPE.COM July 15 (2015). Located at: $\quad$ http://services.runescape.com $/ \mathrm{m}=$ news/come-to-runefest-free-withbonds?allcat=false\&jptg=ia\&jptv=news_list (last accessed Sept. 8, 2015)

(20) J. Benson, RuneScape players donate $\$ 160,000$ to charity. PC GAMES N, December (2014). Located at: http://www.pcgamesn.com/runescape/runescapeplayers-donate-160000-to-charity (last accessed Sept. 8, 2015)

(21) D. Crawley, RuneScape players raise $\$ 160,000$ for charity by dropping coins in a virtual wishing well. VENTURE BEAT December 4 (2014). Located at: http://venturebeat.com/2014/12/04/runescape-players-raise-160000/ (last accessed Sept. 8, 2015)

(22) MMG - Myths and misconceptions, RUNESCAPE.COM, April 14 (2014). $<$ http://services.runescape.com/m=forum/a=14/forums.ws?294,295,309,65341957 $>$ (last accessed Sept. 8, 2015)

(23) J. Hansen, Debt lurks in the lair of dragons. The Australian, December 222012. <http://www.theaustralian.com.au/news/debt-lurks-in-the-lairs-of-dragons/storye6frg6n6-1226542293087> (last accessed Sept. 8, 2015) 
(24) Turning gamers into gamblers. THE AGE June 21 (2012). <http://www.theage.com.au/digital-life/games/blog/screenplay/turning-gamersinto-gamblers-20120620-20obm.html > (last accessed Sept. 8, 2015) 